\title{
La industria del cuero en la Villa y tierra de Madrid a finales de la Edad Media
}

\author{
Concepción Mendo Carmona *
}

La artesanía del curtido fue una de las industrias de más arraigo en la Villa. Oliver Asín remonta sus orígenes al momento de la fundación de Madrid como ocurrió en otras ciudades musulmanas ".

Madrid reunía todas las condiciories necesarias para el desarrollo de esta industria: además de abundante ganado, disponia de cantidad de agua para la instalación de tenerias y de ingredientes para la curtición.

Las curtidurías se abastecian todo el año de las pieles de los animales sacrificados para el aprovechamiento cárnico. Más adelante se analizará detalladamente este punto, pero es necesario resaltar la vinculación existente entre los carniceros obligados y los curtidores de la Villa, ya que los primeros proporcionaban a estos últimos la mayor parte de la materia prima de su artesanía.

En cuanto a la disponibilidad de agua, no es necesario señalar la importancia de la red hidrológica que alimenta Madrid. Esta red está compuesta básicamente por los cursos del Jarama, Henares y Manzanares, pertenecientes a la cuenca del Tajo, cuyos cauces sirven de eje a una serie de arroyos afluentes que discurren por la Villa y tierra posibilitando la instalación de tenerias en sus márgenes ${ }^{2}$.

Centro de Estudios Históricos. Consejo Superior de Investigaciones Científicas.

- Notas para la historia de la industria madrileña desde la fundación de la Villa hasta 1400, Madrid 1963, pág. 44.

2 A. TORREBLANCA LOPEZ, "Fui sobre agua edificada", El aprovechamiento del agua en Madrid y su tierra en la Edad Media, Madrid 1987 (inédito), hoja 4. 
Finalmente, hay que decir que Madrid y su tierra contaban en aquella época con numerosos arbustos de zumaque e inmensos bosques de quercus, plantas ricas en tanino, principal curtiente. Además de otros productos como la sal o la cal, que obtenían de los cercanos lugares de las actuales provincias de Guadalajara y Toledo, respectivamente.

\section{OFICIOS DEL CUERO}

Por industria del cuero hay que entender todo el conjunto de actividades relacionadas con el proceso del curtido de las pieles y cueros y su conversión en artículos manufacturados para el uso diario. De ellas derivan una serie de oficios de los que se trata a continuación, agrupados en tres apartados distintos: curtiduria, zapateria y otras artesanías.

\subsection{Curtiduria}

El proceso del curtido de las pieles y cueros consiste en disminuir la epidermis, el pelaje y las particulas de carne de las pieles y, posteriormente, darles un tratamiento con el fin de que no se pudran ni partan ${ }^{3}$. En época medieval el procedimiento variaba según el tipo de corambre de que se tratara y el producto que deseara obtenerse. Para tratar los cueros vacunos la técnica comenzaba por el desangrado y eliminación del pelo sumergiéndolos en una mezcla de agua y cal -pelambredurante un tiempo que oscilaba entre un mes o mes y medio, según fuera verano o invierno. Esta operación debia realizarse bajo techado para evitar que los cueros se quemaran por efecto del sol. A continuación, se eliminaban los restos de grasa y carne que pudieran quedar en ambos lados de la piel -la flor y la carne-. Posteriormente, se maceraban en alumbre durante un dia, si era verano, o dos, si era invierno; raspándolos y puliéndolos de nuevo, antes de introducirlos en una tinaja con agua y zumaque en rama, y después echarlos en los noques con la 373.

${ }^{3}$ N. J. G. Pounds, Historia económica de la Europa medieval, Barcelona 1981, página 
corteza molida del mismo curtiente durante dos meses o mes y medio, según la estación del año de que se tratase.

Para obtener el cordobán, las pieles de cabra eran remojadas y raídas con cuchilla antes de sumergirlas en una mezcla de agua y cal apagada, hasta conseguir eliminar toda vellosidad. Una vez hecho esto, se introducian en agua con cal viva durante quince dias, si se hacia en verano, y un mes si era invierno. A continuación, se descarnaban y cocian en agua limpia a fin de eliminar los restos de cal; luego se adobaban con alumbre, antes de ser raídos y pulidos de nuevo. Se cosia un juego de pieles para sumergirlas en el zumaque bien molido. Superada esta operación, y bien curtidos los cueros a juicio de los veedores, se sacaban de los noques y descosían las piezas.

Para el curtido de las badanas, se seguia el mismo procedimiento. Con la diferencia de que el raido y pulido de estas pieles se efectuaba una sola vez ${ }^{4}$.

No sólo se utilizaban estas técnicas para la preparación de las pieles, sino que existían otras especialidades dedicadas también a la artesanía del cuero. Una de éstas era la de "zurrador». Su trabajo consistía en rebajar las pieles, afeitando la superficie, con la finalidad de producir un cuero fino y flexible ${ }^{5}$. El instrumento propio de esta actividad era un pedazo grueso de madera llamado garatusa. Con él separaban el pelo o la lana de las pieles y conseguían darles mayor flexibilidad, a continuación eran suavizadas con grasas ${ }^{6}$.

El oficio de zurrador aparece en la documentación claramente diferenciado del de curtidor, pero no bien definido ${ }^{7}$. La legislación por la que se regía fue la misma que la del resto de los corambreros y su trabajo se desarrollaba también en las curtidurías. Se les distingue claramente a partir de 1528, fecha en la que tuvieron ordenanzas propias ${ }^{8}$. Sin embargo, ya desde época anterior se les venía prohibiendo trabajar con los

${ }^{4}$ Archivo de Villa, Secretaría, 2-308-23.

${ }^{5}$ N. J. G. Pounds, Historia económica...., pág. 373.

${ }^{6}$ En Madrid estaba prohibida la utilización de sebo de caballo o de ninguna otra bestia, salvo el de cerdo. Documentos del Archivo General de la Villa de Madrid, ed. de T. Domingo Palacios, t. III, Madrid, 1906, pág. 567.

Archivo de Villa, Secretaría, 2-309-9. Véase apendice documental y Secretaría, 2308-23.

${ }^{8}$ M. CAPELLA, La industria en Madrid. Ensayo histórico-Crítico de la fabricación y artesanía madrileña, I, Madrid 1962, págs. 265-266. 
curtidores conjuntamente en sus tenerías porque "podrían encubrir mucha y mala falsa obra, con la dicha zurraduría" ".

El Concejo ejerció siempre un fuerte control sobre la industria del curtido, no sólo mediante la fijación de los precios de venta sino también a lo largo de todo el proceso de elaboración, como se explicará al hablar del control de la calidad.

La preparación del cuero se desarrollaba en locales dispuestos para la realización de este trabajo, llamados curtidurías o tenerías. Ya se ha dicho que esta labor exigía grandes cantidades de líquido y su constante renovación al ensuciarse rápidamente de restos orgánicos. Por ello las curtidurias necesitaban estar situadas en lugares donde la presencia de agua fuera constante, por ejemplo aprovechando los remanentes de las fuentes públicas, que eran recogidos mediante atarjeas en grandes pilares construidos dentro de las tenerias. Una vez usada este agua se vertía en las arroyadas y escorrentias existentes en las calles de la Villa, o bien, mediante sumideros era conducida al viaje de donde procedía ${ }^{10}$.

En el interior de la Villa y siempre próximas a grupos de fuentes o arroyos se situaban la mayoría de las curtidurías madrileñas. Siguiendo las investigaciones de Urgorri Casado, se pueden señalar al menos dos lugares donde se ubicaban con preferencia: la calle Arenal y la zona de los Caños del Peral. Las situadas en los márgenes del arroyo del Arenal eran más antiguas y, según las relación de Montalvo, serian un total de nueve. Se extendian por la zona próxima a la puerta de Valnadú y a la derecha de la actual calle Arenal ${ }^{\text {" }}$.

Por su parte, A. Torreblanca ${ }^{12}$ señala la existencia de al menos cuatro áreas geográficas principales de fuentes y una marginal, alrededor de las cuales se agruparían otro número indeterminado de tenerías:

a) Puerta de Valnadú, zona extramuros de la Villa, que iría desde el convento de Santo Domingo hasta esta puerta y la torre de Alzapierna. En el nomenclátor de Madrid sus restos son las actuales calles de la Priora y de los Caños del Peral.

b) Arrabal de San Martín, frente a la puerta de Guadalajara, entre las actuales calles Mayor y Arenal, teniendo como eje principal la calle de la Escalinata.

${ }^{9}$ Archivo de Villa, Secretaria, 2-241-52.

10 A. TORREBlanCA LOPEZ, El aprovechamiento del agua..., hojas, 43-44.

"M. CAPELla, La industria en Madrid, págs. 33-34.

12 A. TORREblanca LOPEZ, El aprovechamiento del agua..., pág. 28. 
c) Colación de San Pedro, actualmente plaza de Puerta Cerrada. De aquí salía el grupo marginal que aprovechaba el remanente de aguas de este principal y que desembarcaba en la fuente de los Caños Viejos.

d) Huertas de Atocha, al sureste del arrabal, en las cuales desembocaría el arroyo que discurría por la actual calle de la Ribera de Curtidores, rodeando Madrid desde los actuales Paseo del Prado a Puerta de Toledo.

La concentración de tenerias junto a las fuentes creaba, con sus numerosos desechos, un gran problema a la Villa al contaminar el agua, que pasaba a ser un foco de infecciones y epidemias. Además, despedían fuertes y desagradables olores, lo que las convertía en elementos perniciosos para la salubridad pública, sobre todo en los meses de verano cuando se reducía el aforo de las fuentes y el agua estaba prácticamente estancada.

El cada vez mayor número de tenerías y la insistencia concejil en materia de salubridad, llevó al doctor de Briviesca a ordenar el cierre de algunas tenerías. El 25 de julio de 1489 se ordenó a Fernando de Salmerón hacer una relación de las tenerias causantes de la contaminación, sobre las que se debia aplicar la sentencia. Posteriormente, se estimó que la medida era demasiado rigurosa y perjudicaba enormemente a sus dueños, por lo que se ordenó que permanecieran abiertas ${ }^{13}$.

La situación continuó agravándose y el 14 de julio de 1495 el Consejo Real expidió una provisión ordenando que, en beneficio de los vecinos de la Villa y por motivos de salubridad, se trasladasen las tenerías a los arrabales ${ }^{14}$. En principio, el Concejo dio un plazo a los curtidores para buscar fuera de la Villa lugar donde instalar las nuevas tenerias; finalizado aquél, el corregidor señalaría el sitio donde deberían construirse ${ }^{15}$. Parece que fue esto último lo que ocurrió porque en un acuerdo de 11 de enero de 1496 se mencionan las fuentes de Atocha y el camino de Alcalá como los lugares designados por el Concejo para la nueva ubicación de las tenerias ${ }^{16}$. Los curtidores no debian tener inten-

${ }^{13}$ Libros de Acuerdos del Concejo madrileño, t. Il (1486-92), ed. y comentarios de A. Gómez Iglesias, Madrid 1970, págs. 156-157.

14 A. Millares Carlo, "Índice y extractos de los Libros de Cédulas", en Contribuciones documentales a la Historia de Madrid, Madrid 1971, pág. 136.

${ }^{15}$ Libro de Acuerdos del Concejo madrileño, t. III (1493-98), ed. C. Rubio Pardos, T. Moreno Valcárcel, C. de la Fuente y E. Meneses Garcia, Madrid 1979, pág. 183.

${ }^{16}$ Libros..., III, pág. 203. 
ción de trasladarse pues para esta fecha ninguno había decidido empezar a edificar. Por este motivo, Francisco de Luzón, Pedro Ruiz de Alarcón, Alonso del Mármol e Iván de Vargas ${ }^{17}$ se ofrecieron a dar un plazo de ocho días, en el transcurso de los cuales los curtidores deberían comenzar a levantar las tenerias en el lugar señalado por el corregidor; de lo contrario, ellos se ofrecían a construir "a su costa e misión" las curtidurías necesarias para el servicio de la Villa. Además, tendrían derecho a alquilarlas a los curtidores, naturalmente a precios justos tasados por el Concejo; e incluso a contratar curtidores fuera de la Villa, si los oriundos no consentían con esta medida, a fin de que Madrid no quedara desabastecida de cueros y de hacer rentable su inversión ${ }^{18}$.

El ofrecimiento de estos particulares fue empleado como amenaza para presionar a los curtidores de la Villa ${ }^{19}$. Otra medida acordada por parte del Concejo consistió en prohibir a los dueños de estos establecimientos echar a curtir nuevas corambres. De manera que no se les permitía realizar el trabajo si no era en los nuevos locales situados en los arrabales, de otro modo se arriesgaban a ser expulsados de la Villa ${ }^{20}$.

A partir de este momento hay constancia de que los curtidores comenzaron a obligarse a construir las tenerías extramuros. El Concejo, por su parte, les concedió licencia para curtir en las tenerías de intramuros, en tanto que edificaban las nuevas ${ }^{21}$.

Las ordenanzas de curtidores y zurradores más antiguas que se conservan en el Archivo de Villa datan de 1484 y están incluidas en otras fechadas en 1489. Este año, ante la necesidad de resolver un problema surgido con un vecino de Torrejón, se revisaron las ordenanzas antiguas y se completaron con nuevas disposiciones. En esta nueva normativa se contemplaban algunos casos no estipulados hasta entonces por la ley, pero que se vivian cotidianamente en la Villa. Posteriormente, entre 1493 y 1494 las ordenanzas fueron nuevamente completadas con algunas leyes. Por tanto, se pueden señalar tres etapas en la elaboración de las normas por las que los curtidores hubieron de regirse hasta 1500 aproximadamente $^{22}$.

"Personajes influyentes, quizá regidores.

${ }^{18}$ Libros..., II!, pág. 203.

19 Esto se desprende del acuerdo adoptado en 9 de marzo, por el que el Concejo se decidió a entregarles sitios libres "sin precio", para que en el plazo de una semana trasladaran sus talleres; Libros..., III, pág. 226.

${ }^{20}$ Libros..., III, pág. 226; acuerdo del 20 de abril de 1496.

${ }^{21}$ Libros..., III, págs. 235, 236, 254 y 263.

22 Véase en el apéndice el documento; Secretaría, 2-308-23. Las ordenanzas de 1494, 
Las ordenanzas de 1484 recogen, bajo el título Leyes de la corambre antigua, un total de doce disposiciones de las cuales seis son relativas a corambre, dos a calzado, una a zurradores y el resto se refieren a las funciones de los veedores.

En 1489 se aprobaron las ordenanzas antiguas y, en cumplimiento de ellas, se efectuó el nombramiento de veedores. Se fijó la pena a pagar por el número de navajadas que se dieran indebidamente en los cueros. Se legisló, finalmente, acerca de las pieles que se traían a curtir a la Villa y de las condiciones para que una vez curtidas pudieran sacarse fuera de Madrid.

Por lo que respecta a la normativa añadida en 1493 iba referida a las funciones de los veedores en lo relativo al control que debian ejercer en el proceso del curtido. Hay que reseñar, como novedad, el número elevado de preceptos dedicados al calzado. Se regulaba en estas ordenanzas la exportación del calzado fuera de la Villa, con medidas semejantes a las señaladas para la corambre. Otro grupo de normas establecían el modo como se había de confeccionar el calzado, vigilando muy estrictamente que no se cometiera fraude en la materia prima utilizada.

Posteriormente, en 1494, el Concejo puso de nuevo por escrito las ordenanzas por las cuales desde antaño venían regulándose los curtidores y zapateros de la Villa. La razón de esta recopilación fue una provisión de los Reyes Católicos por la que mandaban que se diera una normativa por la que debía regirse el oficio de curtiduria. Estas ordenanzas serian selladas por el procurador de la Villa ante los monarcas y su Consejo.

Se pueden distinguir dos partes, una de ellas va referida a los curtidores y zurradores, la otra está integramente dedicada a los zapateros.

\subsection{Zapatería}

A la sombra de las tenerías se desarrolló la industria del calzado. En un principio estuvo unida a la del curtido y pellejeria, puesto que las

aquí contenidas, vienen a coincidir en su contenido con las de 1493 y se complementan con las de policía urbana publicadas por T. Dorningo Palacios en Documentos del Archivo de Villa, III, págs. 565-71. Estas ordenanzas de policia urbana del año 1500 han sido estudiadas, también, por E. Corral Garcia, Ordenanzas de los concejos castellanos. Formación, contenido y manifestaciones (s. XIII-XVIII), Burgos 1988, págs. 144-45. 
disposiciones que regulaban la confección y venta de calzado eran las mismas por las que se regían estos oficios, y daban instrucciones respecto a la íntima relación que debia existir entre los tres. Hasta 1546 no se aprobaron unas ordenanzas exclusivamente para zapateros ${ }^{23}$, aunque desde 1493 en la legislación concejil se aprecia la clara diferencia que el Municipio establecía ya entre ambas industrias ${ }^{24}$.

Sin embargo, el hecho de no contar con ordenanzas propias no fue óbice para el desarrollo de esta artesanía que, bajo la denominación común de zapateros, agrupaba a oficiales especializados en diversos tipos de calzado. Tal es el caso de "borceguineros" ${ }^{25} 0$ "chapineros" ${ }^{26}$, dedicados a la elaboración de borceguíes y chapines, respectivamente.

Todos los artesanos estaban sometidos a una común y rígida normativa para la fabricación del calzado. Entre otras disposiciones estaba la prohibición de labrar calzados con pieles mal curtidas, estableciéndose severas sanciones con multas y decomiso del género y de la materia prima para quien así trabajara ${ }^{27}$. Como sabemos, el cordobán era el mejor cuero para el calzado, pero debía ser frecuente utilizar cuero de carnero, cuyo costo era menor, y venderlo por cordobán. Igualmente se penaba a quien vendiera carnero por cervino.

En cuanto al cosido de las distintas partes, ya fueran de zapatos, borceguíes o botas, estaba legislado que se realizase con hilo de cáñamo por su mejor calidad y mayor duración.

Parece ser que existían unas tablas de cuero que servian de plantillas para el cortado de las piezas, según modelo y tamaño. También aquí debia ser frecuente el engaño a tenor de las severas sanciones impuestas a cuantos tuvieran cortas las plantillas o sacaran escasas las piezas.

Asimismo, tenían que respetar numerosos preceptos respecto a la forma como debian ser cada uno de los distintos tipos de calzado que realizaban ${ }^{28}$.

${ }_{23}$ M. Capella, La industria en Madrid..., pág. 276.

${ }^{24}$ Archivo de Villa, Secretaría, 2-308-23, y Documentos del Archivo de Villa, III, páginas. $565-71$.

${ }_{25}$ Libros de Acuerdos del Consejo madrileño, t. I (1464-85), ed. de A. Millares Carlo y G. Artiles Rodriguez, Madrid 1932, págs. 246, 248, 249, 256, 265, 277, 279, 344, 354 y 375 .

${ }^{26}$ Libros..., I, págs. 37 y 197.

${ }^{27}$ Libros..., I, págs. 65 y 182; y Archivo de Villa, Secretaria, 2-308-23. 308-23.

${ }^{28}$ Documentos del Archivo de Villa, III, págs. 568-71, y Archivo de Villa, Secretaria, 2- 
También se legisló sobre la reparación del calzado, lo que se ha dado en llamar "zapateros de viejo o remendones" ${ }^{29}$. Se estipulaba que el arreglo del zapato se hiciera con el mismo tipo de material que lo caracterizaba. Se castigaba muy duramente reparar zapatos de cordobán con piezas de badana por el fraude que esto suponía ${ }^{30}$. Estaba, además, prohibido echar piezas nuevas con suelas viejas, y todo el calzado "sobresolado" debería hacerse forrado, con barretas en los lados y capillos en las puntas. En cuanto a las suelas, cada tamaño de zapato debia arreglarse con la suya correspondiente, no sólo en longitud, sino también en grosor, ya que al calzado pequeño le correspondian suelas delgadas y viceversa ${ }^{31}$. Además existía toda una clasificación del calzado basada en una numeración por puntos, que son nuestras actuales tallas ${ }^{32}$.

\subsection{Otras artesanias}

En este apartado se inciuyen otros oficios caracterizados también por el trabajo del cuero tales como: pellejeros, boteros, guanteros, guarnicioneros, agujeteros, etc.

Como se verá, en general, no alcanzaron hasta época posterior el desarrollo de las industrias anteriormente tratadas. En las fuentes documentales el número de referencias a ellos es mínimo hasta bien entrado el siglo XVI, y las escasas menciones a estos trabajadores se incluyen en las ordenanzas de curtidores y zapateros.

Pellejeros: actividad relacionada con el trabajo de las pieles que tuvo orderianzas desde $1503^{33}$. No se puede precisar con exactitud cuál era el objeto de este trabajo, pues esta normativa, que velaba por la calidad de la materia prima y la cualificación de sus trabajadores, no indica casi nada acerca del modo de ejecución de las obras. No obstante, todo parece indicar que eran estos artesanos los encargados de la preparación del cuero y las pieles para la elaboración tanto de prendas de abrigo como de piezas de armamento defensivo: petos y otras prendas de cuero

29 M. Capella, La industria en Madrid..., pág. 283.

30 Archivo de Villa, Secretaria, 2-308-23, y Documentos del Archivo de Villa, III, pág. 569.

31 Documentos del Archivo de Villa, III, pág. 570.

32 Libros..., I, págs. 247-48 y 341-42; y Archivo de Villa, Secretaria, 2-308-23.

${ }^{3}$ Documentos del Archivo General de la Villa de Madrid, ed. T. Domingo Palaciós, t. IV, Madrid, 1909, págs. 53-63; L. SÁNCHEZ BELDA “Los Reyes Católicos y el gremio de la piel». Piel. Revista española de la industria de la piel, 22-23 (1946), págs. 137-139. 
mucho más asequibles que las de metal y menos pesadas, muy efectivas como protectores en la guerra.

Estas ordenanzas de 1503 fueron promulgadas por la reina Isabel. En ellas hay toda una normativa relativa al nombramiento de veedores del oficio y sus funciones. Se ordenaba que anualmente los oficiales pellejeros eligieran dos personas idóneas para el desempeño de este cargo. Entre los deberes a ellos encomendados hay que destacar la obligación de examinar a los nuevos pellejeros antes de poner tienda, así como a los que la hubieran instalado en los cinco últimos años. Asimismo, eran los encargados de vigilar el proceso del curtido de las pieles, el abastecimiento de éstas por todos los pellejeros para evitar fraudes y de inspeccionar las obras.

Otro conjunto de disposiciones iban dirigidas más concretamente a los oficiales de pellejería, reglamentando el desempeño de su oficio. Como ya se ha dicho, ningún pellejero podia instalar tienda sin pasar el examen previo. Se prohibia, además, que realizasen trabajo alguno para el que no hubieran sido examinados. Se estipulaba el número de «varas» según el cual habian de confeccionar las cotas y se les exigía someterse a la inspección de los veedores.

Finalmente, un tercer grupo de normas estaba destinado al buen abastecimiento de la materia prima de esta industria. Las ordenanzas velaban porque las pieles estuvieran a disposición de todos los oficiales de pellejería, prohibiendo que se adquiriesen para su especulación. En este sentido se ordenaba la edificación de una casa destinada a la venta de corambre a los trabajadores de la piel, lugar donde debian concentrarse todas las pieles que se trajesen a vender a la Villa. Asimismo, se obligaba a los oficiales que dispusieran de materia prima suficiente la pusieran a disposición de los pellejeros que carecieran de ella a los precios estipulados por los veedores.

Boteros: no se reconocieron como oficio independiente hasta el siglo XVII, en que tuvieron incluso calle propia. Hasta ese momento, estos artesanos dedicados a la fabricación y venta de botas y pellejos para vino, aceite, etc., compartían reglamentación con los pellejeros ${ }^{34}$. Dentro de este grupo tendriamos que hablar también de los odreros, pero a pesar de que están documentados no se han encontrado datos de su quehacer profesional ${ }^{35}$.

${ }^{34}$ M. Capella, La industria en Madrid..., pág. 284

${ }_{35}$ A este respecto pueden consultarse los Libros de Acuerdos, en los que se encuentran menciones frecuentes a ellos. 
Guanteros: aunque legalmente no constan como oficio hasta el siglo XVII, hay noticia de la existencia de guanteros en la Villa desde el siglo $X V^{36}$. No se han encontrado datos sobre su actividad. Villa ${ }^{37}$.

Otro tanto ocurre con los "guarnicioneros" y "agujeteros" de la

\section{CORPORACIONES PROFESIONALES}

Como todos sabemos en Castilla las corporaciones profesionales no llegaron a tener tanto control sobre la actividad artesanal como en la Corona de Aragón, debido a la fuerte intervención del poder político, representado por los municipios, por lo que se desarrollaron bajo el control concejil ${ }^{38}$. Algunos autores ${ }^{39}$ establecen dos condiciones que han de darse en cada oficio para poder hablar de corporación:

a) Ordenanzas profesionales y laborales.

b) Autoridades internas que hagan cumplir esas ordenanzas.

a) Por lo que se refiere al caso madrileño, como se ha ido exponiendo a lo largo de este capítulo, los distintos oficios de la piel contaron con ordenanzas y disposiciones que regulaban su trabajo. Esta normativa velaba no sólo por el control de la calidad de la materia prima utilizada, sino también por el procedimiento de su elaboración a fin de obtener un producto final en óptimas condiciones para su comercialización y evitar el fraude. Asimismo, en las ordenanzas dadas en 1500 por los monarcas a la Villa es cuando por primera vez se habla de la necesidad de examinar a los oficiales que querían poner tiendas, tanto curtidores como zapateros ${ }^{40}$. Sin embargo, al igual que señala M. Capella, mi opinión es que estas normas, emanadas del poder real o municipal, no eran en si

${ }^{36}$ M. CAPELLA, La industria en Madrid..., págs. 272-74.

${ }^{37}$ M. CAPELLA, La industria en Madrid..., págs. 267 y ss.

38 M. A. Ladero QueSADA, "España en 1492", Historia de América Latina. Hechos. Documentos. Polémica, Madrid 1978, pág. 85.

${ }^{39} \mathrm{~J}$. González Rubio, "Formación y evolución de los gremios", Revista de Trabajo (1944), págs. 1086-99; A. RUMEU DE ARMAS, "Los gremios españoles. Su origen y vicisitudes", Revista de Trabajo (1945), págs. 189-94; y M. A. LADERO QueSADA, "La ciudad medieval (1248-1492)", Historia de Sevilla, 2, dirig. por F. Morales Padrón, Sevilla 1976, pág. 79.

${ }^{40}$ Documentos del Archivo de Villa, III, pág. 571. 
ordenanzas gremiales aun asemejándose mucho a las normas reguladoras de los gremios propiamente dichos; eran tan sólo disposiciones dictadas por el poder público para el buen gobierno de la localidad ${ }^{41}$. Estas ordenanzas se deben a la obra emprendida por los Reyes Católicos de recopilación y normalización de leyes hasta entonces dispersas e incompletas. Tarea que contribuyó al desarrollo posterior de gremios semejantes a los existentes en la Corona de Aragón ${ }^{42}$.

b) En cuanto a las autoridades que vigilaban el cumplimiento de estas ordenanzas destaca la figura de veedor. Como ya se ha dicho repetidas veces a lo largo de este capitulo, era el encargado de la inspección de los oficios y del cumplimiento de sus normativas. Sobre ellos recaia el control de la calidad durante todo el proceso de elaboración, el control de la saca de materias primas o productos manufacturados fuera de la Villa, etc. Atendiendo a los datos de que dispongo, se puede pensar que en Madrid el veedor no era un cargo gremial sino concejil: el nombramiento corría a cargo de los regidores, como cualquier otro cargo concejil, y debia recaer en dos personas elegidas entre los caballeros y escuderos de la Villa. Su salario se libraba a cargo de los propios del Concejo y en caso de no desempeñar correctamente el oficio quedaban inhabilitados para ejercer éste y cualquier otro cargo municipal ${ }^{43}$. Como en la mayoría de las ocasiones, no eran expertos en la artesanía a inspeccionar, contaban con personas conocedoras del oficio que les ayudaban a juzgar las piezas; sólo más adelante comenzó el Concejo a nombrar oficiales artesanos, propiamente dichos, para el desempeño del cargo de veedor. Así sabemos que en las ordenanzas de 1503 promulgadas por la monarquia para el arte de pellejería, el cargo de veedor recaería en personas del oficio elegidas por los propios artesanos ${ }^{44}$. Hay datos, sin embargo, para creer que la aplicación de esta norma no tuvo efecto. En 1544, fecha en que por primera vez encontramos una mención sobre la existencia de un cabildo de zapateros, éstos solicitan al monarca que se les permita elegir anualmente a dos veedores y dos examinadores

${ }^{4}$ M. CaPelLa, Los cinco gremios mayores de Madrid. Estudio crítico-histórico, Madrid 1957, pág. 7. También se manifiesta así E. Corral Garcia, Ordenanzas de los Concejos castellanos..., pág. 119.

${ }^{42}$ M. A. LADERO QueSADA, España en 1492..., pág. 86.

${ }^{43}$ Libros..., I, pág. 182; y Archivo de Villa, Secretaria, 2-309-9, documento del apéndice.

${ }^{44}$ Documentos del Archivo de Villa, IV, págs. 53-63, y Sanchez Belda, L., Los Reyes Católicos..., págs. 137-39. 
del oficio. Esta petición prueba, una vez más, que aún entonces el oficio carecia de sus propias autoridades internas ${ }^{45}$.

Teniendo en cuenta 10 anteriormente expuesto, me inclino a pensar, como la mayoria de los autores que han tratado sobre la existencia o no de gremios de la Villa durante la Edad Media, que tal realidad no se dio hasta fechas posteriores. Para la época que nos ocupa se puede hablar de oficios regulados por el poder público significado en la figura del Concejo. Para M. Capella ${ }^{46}$ a las ordenanzas gremiales propiamente dichas precedieron los privilegios y autorizaciones del poder real y municipal regulando la vida artesanal de la Villa. La diferencia entre estas medidas y las gremiales es que las últimas buscaban la conservación y defensa del gremio, mientras que las primeras tenían como fin el interés público.

Por su parte, Pastor Mateos ${ }^{47}$ al tratar de los zapateros madrileños habla de la existencia del primer atisbo corporativo de la vida artesanal de la Villa, si bien redunda en la afirmación de la no constitución de gremios.

De los autores que más atención han dedicado a Madrid en sus investigaciones, junto con los trabajos de los anteriores, hay que destacar a Montero Vallejo ${ }^{48}$, quien se inclina por asegurar que en el Madrid medieval hubo una organización gremial desarrollada. Afirmación que basa en el análisis de las ordenanzas a las que atribuye un origen gremial. Opinión que no comparto, pues, por todo lo expuesto, es obvio que estas ordenanzas emanaron directamente del Concejo o por orden de la monarquia.

\section{PROTECCIONISMO EN LAS MANUFACTURAS DEL CUERO}

\section{1. "Politica económica» de la Villa}

Hablar de "política económica" en la Edad Media es un anacronismo ${ }^{49}$, sin embargo, he optado por esta expresión por parecerme la

\footnotetext{
${ }^{45}$ Archivo de Villa, Secretaría, 2-244-1; representación hecha por la congregación de San Crispin.

${ }^{46}$ Los cinco gremios mayores..., pág. 78.

47 "Noticia sobre la organización profesional en Madrid". Revista de la Biblioteca, Archivo y Museo del Ayuntamiento de Madrid, XIX (1950), pág. 276.

${ }^{48}$ El Madrid medieval, Madrid 1987, pág. 256.

${ }^{49}$ M. A. Ladero Quesada, España en 1492..., pág. 90. Sobre la cuestión de si es lícito
} 
más adecuada para referirme a los criterios económicos que siguieron los concejos medievales. Sea como fuere, lo cierto es que la regulación económica de la vida madrileña se guió por dos principios: la defensa del comercio y la defensa del consumidor.

\subsubsection{La defensa de los intereses del comercio}

En la Baja Edad Media, el desarrollo de los medios de comunicación, la mejora de las facilidades del mercado y la especialización industrial de algunos centros obligó a los municipios, para mantener la rentabilidad comercial, a adoptar controles artificiales y proteger la industria y el comercio propios mediante una "política" consciente ${ }^{50}$.

Se pretendia con ella aumentar los ingresos de la ciudad y asegurar abundante y barato aprovisionamiento a los consumidores locales. Estas medidas basadas en la protección de la producción y la limitación de las importaciones se transmitieron a la Edad Moderna, siendo algunas de las ideas en que se asentó la economia mercantilista que caracterizó esta época ${ }^{51}$.

En el caso de la industria del cuero las normas para la protección de esta importante artesanía se centraron en la prohibición de la exportación de curtidos y calzado fuera de la Villa y tierra y en la conservación del prestigio de sus cueros para preservar su arte de la decadencia y acreditar su industria ${ }^{52}$.

En las ya citadas ordenanzas de curtidores y zapateros se prohibía a los vecinos de la Villa y tierra de Madrid, así como a los forasteros, sacar fuera de ella ningún tipo de piel curtido o sin curtir, así como cualquier género de calzado. Además, se negaba a los regidores la posibilidad de otorgar licencia para permitir la salida de esta mercancía. La prohibición no afectaba a las pieles traídas a curtir a la Villa. En este caso se podian sacar después de haber solicitado la licencia debida a los regidores y veedores del Concejo y siempre que la Villa quedara

o no hablar de política económica de las ciudades medievales, puede consultarse la introducción del trabajo de HiBbert, A. B., "La política económica de las ciudades", en Historia económica de Europa, dirig. por Sir John Clapham, Eileen Power y otros, Madrid 1948-83.

${ }^{50}$ A. B. HibBert, La politica económica de las ciudades, pág. 202.

${ }^{54}$ Véase, a este respecto el trabajo de J. LaRRAz LoPEz, La época del mercantilismo en Castilla (1500-1700), Madrid 1943.

${ }^{52}$ E. PAStOR MATEOS, Noticia sobre la organización profesional en Madrid, pág. 278. 
suficientemente abastecida de este material. Si esta condición se cumplía, las autoridades competentes -regidores y veedores- expedian una cédula de licencia que era anotada en los libros municipales por el escribano. La finalidad de este largo proceso era llevar cuenta exacta de todo el calzado y las pieles que salian de la Villa, pues por ellas se pagaba un derecho estipulado previamente por el Concejo, que era recaudado por el mayordomo para la hacienda madrileña ${ }^{53}$.

Para facilitar la saca de corambre que se traía a curtir a Madrid se ordienó que cualquier persona que entrara pieles con este fin antes de entregarlas en las tenerias las hiciera registrar ante los veedores por el escribano del Concejo. De este modo se podía llevar mejor el control de los cueros que no eran del ganado de la Villa y posibilitar posteriormente su salida ${ }^{54}$.

Asimismo, ampliando las facultades conferidas a los regidores en disposiciones anteriores, las ordenanzas de 1494 obligaban a todo aquel que quisiera vender corambre fuera de Madrid a solicitar permiso de éstos quienes sólo podrian darlo una vez, asegurado el abastecimiento de los artesanos de la Villa ${ }^{55}$.

Estas medidas proteccionistas perseguian dos objetivos bien calculados por el Concejo: de un lado, evitar que los artesanos especularan con los productos, y de otro, obtener sustanciosos ingresos. Todas las disposiciones concejiles trataban de asegurar el abastecimiento de materia prima a los zapateros y de calzado a los vecinos. Al no permitir la comercialización de estas mercancias fuera de la Villa, se cerraba a los zapateros y curtidores la posibilidad de obtener mayores beneficios con la libre venta de sus mercaderias, ya que de este modo se veían en la necesidad de darlos a los precios fijados por el Concejo.

Por lo que se refiere a los ingresos que proporcionaba esta normativa hay que señalar al menos dos: los derechos a pagar por la saca de cueros y calzados fuera de Madrid y el arrendamiento de las multas impuestas a aquellas personas que no respetaran la legislación referente a la exportación de las pieles y el calzado de la Villa. En relación a esto se sabe que por las ordenanzas de 1489 , se negaba a los carniceros obligados incluir entre las condiciones del contrato por el abastecimiento de carne a la Villa, aquella que otorgaba facultad para sacar fuera de

53 Archivo de Villa, Secretaria, 2-309-9, en apéndice documental, y Secretaria, 2-30823.

54 Ídem.

${ }^{55}$ Archivo de Villa, Secretaria, 2-308-23. 
Madrid las pieles de los animales sacrificados para el consumo alimenticio. Éste era uno de los requisitos más exigidos por los "obligados" a las carnicerias en sus contratos. La ventaja para éstos radicaba en el aprovechamiento, en su propio beneficio, del libre comercio de estas pieles, sin limitación de precios y sin la contrapartida del derecho que se imponía a las personas que solicitaban licencia para sacar cueros de la Villa. Con las medidas adoptadas en 1489 se puso fin a esta práctica de los carniceros obligados y se evitó la pérdida de ingresos derivada de la aceptación de dicha condición ${ }^{56}$.

\subsubsection{La defensa del consumidor}

Los municipios medievales tuvieron siempre el propósito de velar por los intereses de los consumidores locales. Para conseguirlo, las autoridades de la ciudad centraron sus esfuerzos en tres aspectos: abastecimiento, calidad y precios. Toda la legislación concejil giró en torno a asegurar el aprovisionamiento de la Villa, garantizar la calidad de los productos y el control a la baja de los precios. Además, esta línea de actuación garantizaba el desarrollo de la artesanía del cuero que, aunque concentrada en el comercio local, gozaba de gran fama y era comparada con la cordobesa ${ }^{57}$. Mantener el prestigio de las curtidurías y ofrecer a los vecinos buen género fueron las pretensiones del Concejo, como se observa a través de la estricta legislación por la que se rigió esta industria.

\subsubsection{Alhóndiga del cuero}

Las curtidurias se abastecian todo el año, principalmente, con las pieles de los animales sacrificados en las dehesas carniceras y que los curtidores tenían el deber de comprar a los carniceros obligados ${ }^{58}$. Esta imposición no siempre la cumplían los curtidores quienes buscaban, obviamente, los precios más económicos; por esta razón hubo muchas pro-

56 Archivo de Villa, Secretaria, 2-309-9, en apéndice documental.

57 M. Capella, La industria en Madrid..., pág. 36.

58 Libros..., II, pág. 124, y IV, pág. 55. 
testas por parte de los "obligados" porque sus pieles eran despreciadas por los artesanos del cuero ${ }^{59}$.

Hay datos que hacen pensar en la existencia de la figura del «obligado" al abastecimiento de las curtidurias, al menos en el año $1481^{60}$. En este caso, recaian en una misma persona, Juan de Madrid, las obligaciones del abastecimiento de carne y de pieles. La estrecha vinculación existente entre esta industria y la actividad ganadera, desarrollada en el espacio de la Villa y su alfoz, se pone aún más claramente de manifiesto al ser la carnicería la principal abastecedora de la materia prima de esta industria.

Además, los curtidores contaban también con el cuero de los toros corridos en las fiestas ${ }^{61}$, amén de las pieles que personas de lugares comarcanos traían a curtir a la Villa ${ }^{62}$ y que -como se dijo- sólo podian sacar una vez curtidas si la Villa no quedaba falta de corambre. En 20 de enero de 1496 el Consejo Real dio una provisión a la Villa de Madrid para edificar una alhóndiga donde se colocasen los cueros necesarios para el abastecimiento de los zapateros ${ }^{63}$. Unos meses más tarde, otra provisión mandaba al Concejo situar la alhóndiga de los cueros en un lugar conveniente siempre que no fuese junto a los curtidores ${ }^{64}$. En contestación a esta orden la Villa redactó unas ordenanzas para la edificación y funcionamiento de la alhóndiga. Durante el tiempo de su construcción se habilitaría una casa particular para tal efecto.

El objetivo de esta medida era controlar todas las pieles curtidas por los corambreros madrileños y asegurar el abastecimiento de esta materia prima a los distintos trabajadores del cuero. En este sentido, los regidores, justicias y veedores efectuarian un repartimiento entre todos los curtidores para que cada uno aportara un número de docenas de pieles previamiente estipulado. Además, realizarian visitas a las tenerias para elegir los mejores cueros y proceder al repartimiento. Posteriormente, éstos eran marcados con el hierro del Concejo y señalados por cada curtidor para poder identificar la obra de cada uno.

Como en las ordenanzas de zapateros y curtidores, se velaba también en éstas por evitar el fraude y la reventa. Por este motivo, los

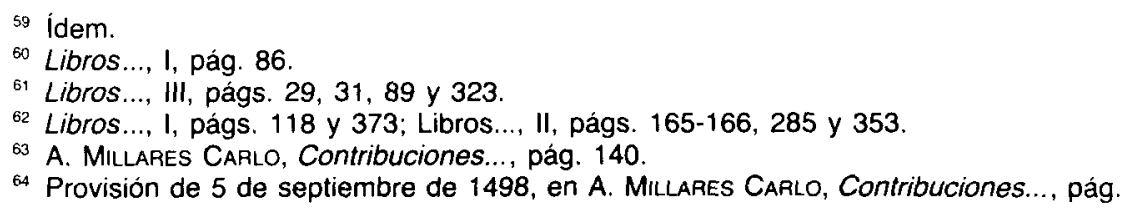


precios eran fijados dos veces al año por el Concejo. Esta tasa se hacía pública y se establecía de acuerdo al costo real de la manufactura y dejando un margen de ganancia razonable para el curtidor.

Los zapateros estaban obligados a abastecerse de los cueros de la alhóndiga. Aquellos más pobres que no pudieran costearse los cueros necesarios para su trabajo podian adquirirlos por fiado.

Parece que en la alhóndiga se adoptaron disposiciones ya existentes y que antes se aplicaban individualmente en cada tenería ${ }^{65}$.

\subsubsection{Control de la calidad}

A lo largo de este capítulo se ha hablado ya de la figura del veedor y sus funciones. Una de las más importantes era el control de la calidad, hasta el punto que se puede decir que en todo el proceso del curtido cada paso dado por los artesanos debía contar con su permiso y realizarse ante la presencia de estos oficiales concejiles. Las ordenanzas exigian a los curtidores que antes de preparar las pieles y los cueros las hicieran sellar por los veedores como garantía de que pertenecian a la Villa y estaban en buenas condiciones para su curtición; además prohibian que se echaran cueros o pieles en las tinas si no era a vista de estos oficiales. Asimismo, pasado el tiempo del adobo, no podian sacarlas de los noques - pilones - sin el consentimiento de los veedores que juzgaban el trabajo antes de dar la autorización ${ }^{66}$. Una vez bien labradas volvían a sellarlas a fin de que los zapateros y los otros usuarios que trabajaban con esta materia prima tuvieran garantías de buena calidad; era ésta, además, una medida del Concejo para controlar las piezas trabajadas en la propia Villa y las que se habian adquirido fraudulentamente ${ }^{67}$.

Por otro lado, los veedores estaban obligados a efectuar visitas a las tenerías sin previo aviso ${ }^{68}$, a fin de inspeccionar el modo de elaboración y la calidad de la materia prima de su artesania en un día normal de trabajo, pues el fraude debia de ser muy frecuente: mostrar un buen producto y trabajar con otros de mala calidad.

65 Archivo de Villa, Secretaria, 2-308-23.

${ }^{66}$ Documentos del Archivo de Villa, III, págs. 565-566, y IV, págs. 57. Archivo de Villa, Secretaria, 2-309-9, en apéndice documental, y Archivo de Villa, Secretaría, 2-308-23.

67 Archivo de Villa, Secretaría, 2-309-9, en apéndice documental.

68 Documentos del Archivo de Villa, IV, pág. 60; Archivo de Villa, Secretaria, 2-308-23. 
Una preocupación constante de veedores y artesanos de la piel fue el número de cuchilladas dado por los carniceros al sacrificar las reses. De una lectura detenida de las fuentes se desprende que los matarifes eran muy descuidados a la hora del despiece y desuello del ganado, por lo que muchas pieles no podían ser aprovechadas por los curtidores debido a la cantidad de cortes que presentaban a causa de la impericia o desmaña de los cortadores. Por este motivo se legisló un número de cuchilladas máximo que podian darse a los animales para separar la piel de la carne ${ }^{69}$. Y se impusieron elevadas penas a cuantos no cumplieran este precepto. Ahora bien, se puede pensar que los matarifes actuaban con intención al desollar los animales. Todo parece indicar que los cueros se vendian por piezas independientemente de! tamaño ${ }^{70}$, de ahí que buscaran un mayor beneficio económico de la venta: a más cuchilladas más piezas que vender.

\subsubsection{Control de los precios}

El Concejo veló con mucho celo por evitar que el precio de los productos consumidos subiera en demasia. Utilizó un sistema directo, estableciendo las tasas a las que se debian vender el cuero y los productos manufacturados derivados de él ${ }^{71}$. En ocasiones, se tiene constancia de que para ese fin era requerida la presencia de curtidores y zapateros en el Ayuntamiento, y con menos frecuencia también la de los carniceros $^{72}$.

Ya en el Ordenamiento de Pedro $1^{73}$ se establecian los precios según el tipo y medida del calzado. Este mismo criterio se siguió empleando años más tarde, como se desprende de los acuerdos de 20 y 25 de junio 1484 en los que el Municipio estipuló muy detalladamente el precio de cada género y tamaño de zapato. La tasa de precios no siem-

${ }^{69}$ Archivo de Villa, Secretaría, 2-309-9, en apéndice documental, y Archivo de Villa, Secretaría, 2-308-23.

70 Libros..., I, págs. 116 y 192.

7 Se ha encontrado en el Archivo de Villa, Secretaria, 2-308-23, una lista de estos precios, que aunque no va fechada se puede situar hacia 1500 . Según ésta el costo del zurrado de una docena de cordobán montaba 170 maravedis.

${ }^{72}$ Libros..., I, pág. 329, y Documentos del Archivo de Villa, ed. Timoteo Domingo Palacios, I, Madrid 1888, págs. 321-44.

${ }^{73}$ Libros..., I, págs. 247-8 y 341-2. En Valladolid se indica en un arancel de 1442 los diferentes tipos de calzado que fabricaban los zapateros y el precio máximo que se podia exigir por cada uno. A. Rucouol, Valladolid en la Edad Media, II, Valladolid, 1987, pág. 431. 
pre fue bien recibida por los zapateros. El 2 de julio del citado año formaron una «liga" para protestar contra la fijación de precios, porque les parecia injusta esta medida no común a otros lugares comarcanos. Los zapateros se negaron a vender con tasa ningún calzado, por lo que exigieron al Concejo establecer nuevos precios, más convenientes a las dos partes, que serian fijados por dos zapateros y dos oficiales de la Villa ${ }^{74}$. Estas tasas se pregonaban públicamente ${ }^{75}$.

Estas medidas, tan poco gratas para los artesanos, tenian por fin evitar los abusos que pudieran cometer con la venta de sus mercadurías, así como la lucha contra los intermediarios.

${ }^{74}$ Libros..., I, págs. 344-5.

75 En el archivo de Villa, Secretaria, 2-308-23, se conserva uno de estos pregones. La falta de secuencia de los mismos nos ha impedido extraer más conclusiones al respecto. 


\section{APÉNDICE DOCUMENTAL}

1489, agosto, 4. Madrid.

Ordenanzas de curtidores y zurradores.

B. A.V., Secretaria, 2-309-9. Contiene Ordenanzas de 1484 , enmendadas en 1489 y completadas en 1493. Su estado de conservación es, en general, bueno aunque tiene algunos folios rotos en sus márgenes.

En la noble e leal villa de Madrid, quatro dias del mes de agosto, año del nasçimiento del Nuestro Señor lhesu Christo de mill e quatroçientos e ochenta e nueve años. Estando ayuntados en la cámara nueva del Ayuntamiento de la dicha Villa, según lo han de uso e de costunbre conviene saber: el honrrado cavallero Juan Pérez de Barradas, comendador en la dicha Villa e su tierra e Francisco Núñez de Toledo e Gonzalo de Monzón e Diego de Vargas, regidores de la dicha Villa e el comendador Pedro de Ayala e Juan de Luxán, el del Arraval, e el dotor de Madrid, letrado del dicho concejo e el alcaide del Pardo e Gonzalo Gómez de Bitoria e el liçençiado Alcalde e el liçençiado de Rojas e Francisco de Vargas e Francisco Solano e Diego de Huete e García Diaz e Juan Ximénez, escrivano, e Fernando de Madrid e Gámez e Carlos de Carraço e el bachiller fijo de Juan de Prado e Juan de Salmerón e Juan de Tapia e Juan de Madrid e Juan de Soria, mayordomo de Francisco Núnez, e Juan, el de Juan Zapata.

Paresçió un ombre de Torrejón que se llama Juan de lllescas e dixo que él truxo a esta Villa a cortir e adobar dos cargas de vadanas e, sacando la una de ellas, le son tomadas por los fieles diziendo que iva sin liçençia de los rregidores e que la avía perdido, e que él no sabía nin supo que oviese ley nin órdenes por donde lo tal deviese perder. Por ende, pidió por merçed a los dichos se- 
ñores que se lo mandasen dar y en él sacar de lo otro que queda; y más, si truxere a cortir e adobar e esta Villa diesen orden commo lo pudiesen sacar sin pena alguna.

Otrosí, juró ante los dichos señores que tiene arrendadas las carneçerias de esta dicha Villa, e dixo que él tiene por condiçión de sacar de ellas e de su tierra la corambre de las reses que matare en las dichas carneçerias, e que ge la perturban diziendo que ay órdenes para que non se saquen de la dicha Villa so pena de perdellas. Por ende, pidió a los dichos señores que le guarden la condisión del dicho arrendamiento que complía por San Juan de junio del año venidero de noventa.

Otrosí, dixo que después del dicho arrendamiento por él fecho, la dicha Villa ordenó e mandó que qualesquier cuchilladas o navajadas que los desolladores diesen en qualesquier cueros vacunos pagasen por cada uno doze maravedís, e de cada cuchillada o navajada que diesen en cada cuero de macho o de carnero o oveja o cabra quatro maravedís. En lo qual él avía perdido porque no hallava desolladores que desollasen sus carneros por miedo de la dicha pena. Pidioles por merçed que mandasen remediar por manera que él pudiese cumplir lo que era obligado, e mostró un cuero de vaca en el qual el desollador avía dado çiertas navajadas que no fera daño del dicho cuero, e dixo que le pidía al arrendador de la pena de las dichas cuchilladas e navajadas más de doze reales. $E$ los dichos señores corregidor e regidores quisieron ver las ordenanças antiguas que esta dicha Villa tiene çerca del dicho curtido, las quales luego fueron y traidas e leidas en presençia de todos los dichos señores; e otrosí, otras ordenanças que por la dicha Villa se fizieron // el año de ochenta e quatro que hizieron veedores para lo suso dicho, su tenor de todo lo qual es este que se sigue:

Leyes de la Corambre antigua.

Ley para que no saquen de Madrid nin de sus arravales cueros al pelo, nin curtidos, ni otros lo puedan sacar de las aldeas salvo para traerlos a la Villa. ${ }^{a}$

Ordenaron que persona nin personas algunas non sean osadas de sacar de Madrid ni de sus arravales cueros vacunos al pelo nin 
cortados, nin otros lo puedan sacar de las aldeas salvo para lo traer a esta dicha Villa. E qualquier que lo sacare que lo pierda e sea de quien lo tomare la meatad e la otra mitad para los muros de esta Villa. E si el que ge lo tomare ge lo tornare al que ge lo tomó o a otro por él, o lo cohechare o lo baratare sea la dicha mitad para el que lo acusare. Tal que así se provare que lo tornó, pague en pena otro tanto como el valor de ello para los muros de esta Villa. Esto se entiende a los veçinos de Madrid que o sean curtidores o otras personas sacaren o levaren fuera.

Ley commo an de sacar los estrangeros las coranbres de esta Villa e su tierra. ${ }^{b}$

Otrosí, ordenaron que si alguna o algunas personas de fuera parte que non sean vecinos de Madrid e de su tierra conpraren algunas de las dichas coranbres de vecinos de Madrid o de su tierra, que los tales vendedores que ge lo vendieron ${ }^{c}$ sean tenudos de los fazer saber estas ordenanças, e faziendogelo saber si los tales forasteros lo llevaron e sacaron fuera de la dicha Madrid e sus arravales que lo prendan como dicho es. $E$ si tales vendedores non ge lo fizieron saber que el forastero non aya pena alguna por lo sacar, para el vendedor o vendedores aya la misma pena susodicha, e que sea estimado el valor de las corambres que asi vendieron e sea tenuda de la pagar, la mitad para quien lo tomare o acusare e la otra mitad para los muros de esta dicha Villa como dicho es.

Ley para las coranbres. Prohibido vender las corambres en las ferias. $^{d}$

Otrosi, ordenaron que por quanto los cortidores e los que conpran corambres guardan las dichas coranbres e las non quieren vender fasta en los dias de las ferias que en esta Villa se fazen, porque entorices lo venden en conpran libremente quien quiere, de lo cual redunda gran daño a los vecinos de esta Villa, especialmente porque los çapateros no pueden aver las dichas coranbres salvo a grandes preçios por cavsa de lo qual se encaresçe mucho el calçado. Por ende, por bien de la republica de esta Villa e su tierra, ordenaron que esta dicha ordenanza estienda tanbién en el tienpo de las ferias commo en todo el otro tienpo del año contra los vendedores que son vecinos de Madrid e de su tierra.

Ley que ningún regidor non pueda dar liçençia para las dichas coranbres. $^{\theta}$ 
Otrosi, ordenaron que los regidores non den nin puedan dar liçençia alguna para sacar las dichas coranbres, e puesto que la dan que non vala. $E$ qualquier persona o personas puedan coger $e$ demandar la dicha pena o penas aunque las tales personas las saquen con la dicha liçençia.

Ley para que pueda ser demandada la pena de la coranbre que se sacare aunque no sea tomada. ${ }^{\prime}$

Otrosí, ordenaron que aunque non sea tomada la tal coranbre al tiempo que se sacaron, que por qualesquier persona o personas pueda ser demandada la tal pena e penas al que lo vendiere 0 al que así lo sacare o amos a dos si fueran vecinos de esta Villa e su tierra.

Ley de los çapateros para que puedan sacar coranbre e çapatos solamente en tierra de Madrid. ${ }^{g}$

Otrosí, ordenaron que los çapateros de esta Villa puedan sacar coranbre para labrar en las aldeas e tierra de Madrid, e çapatos para vender en las aldeas e en los lugares de los señorios de enderredor de tierra de Madrid en presencia de un regidor e del escrivano del conçejo, faziendo juramento la tal persona que lo non quiere salvo para labrar en la dicha tierra. $E$ que, quando más sacare cada vez, non saque más de un cuero cortido e media dozena de badanas e media dozena de cordovanes, e si se probare que los sacó fuera de tierra de Madrid para otra parte que le den pena de perjuro e pague la pena susodicha.

Lo que deven fazer los veedores a quienes se diere sello para los cueros es lo siguiente:

Ley de los cueros e de las carneçerías para que todos vayan marcados al curtir con el dicho sello, entiéndase los buenos e no ios malos.

Primeramente, que todos los cueros vacunos e carneros e ovejunos de qualesquier conjunto otra manera que metieren para las carneçerias de Madrid e de su tierra, que todos vayan marcados con el dicho sello e non se puedan cortir sin él por si vieren que ay en los dichos cueros algunos que sean tales non los marquen / / porque estos tales, non se gasten en Madrid con todas las dichas coranbres que asi marcaren. Ande por escrito e hagan registro e 
libro de ellas porque se conoçieren con las coranbres que los çapateros gastaren. $Y$ que demás de esto, al tiempo de lo sacar del noque non lo saquen sin el veedor.'

Item andar e registrar que ningund çapatero non gaste, ni corte, ni cosa otra coranbre ninguna salvo de lo que estoviere sellado. $E$ quando quier que acaeçiere que esta coranbre sellada fuere acabada de gastar que el çapatero a quien faltare coranbre vaya al veedor o veedores e los diga que no tiene coranbre ni la halla sellada, e que los veedores luego vayan a casa de los cortidores e los hagan dar de las otras coranbres que tovieren al preçio ordenado e que antes de alli lo lieve al dicho çapatero los veedores sellen las tales coranbres por buenas, de manera que en casa de ningún çapatero non se pueda hallar coranbre de ningún género que non sea sellada porque sea buena. $Y$ si se hallare que no es tal sepamos cuya culpa es, si los veedores que la sellaron mala o de los çapateros que a escuso la conpraron sin sellar e sean penados sobre ello. res!

Ley para los çurradores que non çurren cueros de los curtido-

Item registrar las casas de los çurradores e ver si çurran algunas coranbres que no estan selladas, por que estos çurradores no han de çurar coranbre ninguna de cortidor puesto que sea buena, ni los veedores la han de sellar a ningún cortidor // e las coranbres que los çapateros les dieren a çurrar no las han de tomar sin que estén selladas porque sean ralas que se deban çurrar; e asimismo, los çurradores no han de conprar cosa ninguna en Madrid e en su tierra para lo çurrar ellos, pero si lo conpraren de otras partes que lo puedan çurrar notificándolo primero a los veedores para que los sellen de manera que suyo ni ageno puedan çurrar ninguna coranbre sin que primeramente esté sellada.

Ley para los veedores de commo han de servir e la pena que an de aver no faziendo lo que deven."

A estos veedores a de dar la Villa el salario que por todos fuere acordado, an de jurar de lo fazer bien e fielmente. E si al contrario se fallare que pierda el tal ofiçio e sean inabilitados para aver jamas otro ofiçio ninguno de Madrid para que por servir este ofiçio si lo sivviere bien $e^{\prime}$ limpiamente non pierdan qualquier otro 
ofiçio de los de la Villa si los viniere por su suerte commo acostunbra fazer.

\section{Ley de las penas. ${ }^{m}$}

Que de más del salario de la Villa les asentare ayan la terçia parte de las penas e la otra terçia parte sean para los propios de la Villa. E que estas penas en que incurrieren juzguen los dos regidores que en cada mes han de regir e la justiçia e estos vean si es justo lo que los veedores hazen porque a estos se remite todo lo que de este negoçio dependiere juntamente con los // dichos veedores.

Ley de la coranbre que hubiere de sacar de Madrid e su tierra que non saquen de Madrid e su tierra e que se a de labrar."

Que si alguna coranbre se uviere de sacar de Madrid e de su tierra non lo puedan sin liçençia e que esta coranbre non sea de la de Madrid e su tierra porque para esta en ninguna manera se a de dar liçençia. E para la otra que la puedan dar los dos regidores que regidieren con tanto que ellos en persona vayan con los veedores e con el uno de ellos a ver que coranbre es, e quien la lieva; e sepan primero si los çapateros an menester algo de ello, e si lo ovieren menester fazergelo dar a los preçios ordenados y sellándolo primero commo dicho es. E cuando non lo quisieren e non lo ovieren menester que den la dicha cédula de liçençia, la qual non sea por una carga ni por dos ni para más cerradamente si no es específicamente para tantos cueros vacunos e para tantas dozenas de cada una de las otras coranbres, para que sobre cada cosa de esto que así se diere liçençia se an de poner el derecho que la Villa acordare. $E$ que los regidores que tal liçençia dieren en el mes que les cupieren sean obligados jurar por escrito cada çédula que dieren o hazer que lo asiente el escrivano del conçejo en el libro, e lo señalen en ellos cada vez que la dicha çédula dieren porque de aquellos se haga luego el mayordomo, o a la persona que la Villa acordare que reçiba el dicho derecho, cargo. $/ /$.

Que se tome juramento en público concejo a todos los cortidores que de otra manera non sacaren coranbre ninguna escondidamente, porque si lo hizieren de más de la pena que se les pusiere sean avidos por perjuros; si algunos avrá que lo descubran que non se quieren bien todos. 
Ley del calçado que se a de sacar..$^{n}$

Que ningund calçado, ni borzeguís, ni de otra manera non puedan sacar sin liçençia e sin que lo vean los dichos regidores e veedores con ellos por ver que tal calçado es, e registren quanto tienen el que viniere por la tal liçençia por ver lo que sacan, e lo que dexan, e les hagan dexar sus tiendas basteçidas de lo mejor e lo que sacaren sea de lo que no fuere tal, e sea con la dicha liçençia. E si la villa acordare poner derecho alguno sobre ello que sacaren, que se ponga e se tenga la forma en ellos, commo de suso diz en lo de las coranbres.

E después de esto, en la Villa de Madrid, quatro días del mes de junio del año del Señor de mill e quatroçientos e ochenta e quatro años se pregonó todo lo susodicho por Juan de Orgaz, pregonero, estando presente el onrrado cavallero Garcia de la Quadra, corregidor de la dicha Villa, e Pero Núñez de Toledo e Françisco de Luzón e Luis de Alcalá e Gonçalo de Monçón, regidores, e el dotor de Madrid e el bachiller Fernando Díaz, letrados de la dicha Villa, e el dotor de Monçón e el bachiller Jarada e Iván de Vargas e Juan de Tapia e García de Sanzedo e Ferrando de la Piedra e Ruiz Fernández e Martín Rodrigo e Diego de Monçón, escrivanos públicos, e García de Villanueva e Luis de Villanueva e el alcaide Ferrando de Atiença // e Rodrigo de Jaén e Antonio Soler e Antonio de Viana e Ferrando Rodrigo que son de los cavalleros e escuderos de la dicha Villa e Juan de la Porra e Pedro de Coveña e Diego López de Tardajos e Gonzalo Martínez, cerero, e Rodrigo del Monte e Ferrando Nonvela e Juan López, zapateros de los ombres buenos pecheros de la dicha Villa, nombraron por veedores e hesecutores de todo lo susodicho a Juan Salmerón y a Pedro González de Villanueva; de que fueron testigos del dicho pregón Gonzalo de la Torre e Alfonso Maçote e Juan Díaz, vecinos de Madrid.

\section{Leyes nuevas. ${ }^{\circ}$}

E todo lo susodicho visto por los dichos señores corregidor e regidores e cavalleros e escuderos de la dicha Villa e los otros ombres buenos de suso nombrados e platicado bien todo ello, dixeron que les paresçia cosa muy buena e provechosa a la dicha Villa e al bien e pro commun de ella guardarse todo lo susodicho ordenado el dicho año de ochenta e quatro sobre las dichas ordenanças viejas e aver sobre ello. E para la hesecuçión de ello los 
dichos veedores en todo tiempo para siempre jamás e de una concordia acordaron que los aya e que los nombren los regidores, juntándose con los otros ofiçios que an de nombrar por el día de San Miguel de cada año, segund el tenor e la forma de la sentençia del rey don Juan, e que sean de los cavalleros e escuderos de la dicha villa, personas ábiles y suficientes para el dicho ofiçio; e que ayan de salario cada un año quinientos maravedís demás de la parte de las penas que aqui dize que ayan, las quales se les libren de la misma hazienda que serán propios de la dicha Villa. E los dichos Fernán Núnez e Diego Várgas e Gonzalo de Monçón, regidores susodichos, dixeron que nombravan e nombraron para el dicho ofiçio, para de aquí a San Miguel de setiembre primero que viene de este dicho año e para dende un año, a Juan de Salmerón e a Juan de Tapia, veçino de Madrid, con las condiçiones e segund de suso está ordenado. Los quales lo açebtaron e de ellos se reçibió juramento en forma devida de derecho, que usarán del dicho ofiçio bien e fielmente sin cautela alguna.

Otrosi, platicaron sobre la dicha ordenança de las dichas cuchilladas e navajadas nuevamente fecho e dixeron que aquello hera útil e provechoso a la dicha Villa e bien e pro común de ella por evitar a los desolladores que no fagan en los cueros que desollaren ninguna cautela porque les pareçia que la pena hera grande e que la devian moderar e moderaron, que fuere la mitad de ello en esta manera: que de cada cuchillada e navajada que se diere en el cuero vacuno aya de pena seis maravedis; e de los terneros e venados tres maravedis en cada cuero; de cabrones e cabras, carneros e ovejas tres maravedís; e en cada cuero de corderos e corderas un maravedí. E questo sea asentado de tres navajadas o cuchilladas que se dieren en el cuero vacuno arriba, e de los que se dieren en los otros menores arriba, e que se ayan de judgar estas penas por dos // regidores nonbrados de entre los otros regidores por derecho e información de los dichos veedores a los quales se tomare quien sus conçiençias lo vean.

Ley de la coranbre de fuera parte, commo se a de sacar e commo se a de registrar quando se trae, e sellar quando la sacaren. $^{\circ}$

Otrosí, dixeron que por quanto en todas las dichas leyes e ordenanzas viejas e nuevas no ay ley no ordenança para poder 
sacar coranbre alguna traida para adobar a esta Villa de fuera parte e pareçe cosa justa dexarias sacar. Por ende, ordenaron e mandaron que qualesquier personas que algunos cueros vacunos e de terneros $e$ venados e cordovanes e vadanas troxere a esta Villa a cortir e adobar, antes que lo deslie, lo registrar ante los dichos veedores o qualquier de ellos e ante el escrivano de conçejo, el qual sea obligado de hacer libro de los dichos registros e de las liçençias que para sacar la dicha coranbre e otras qualesquier se dieron, e que por ello non lleven derecho alguno, poniendo en el registro quantos cueros e cordovanes e vadanas registra porque para aquellos sacar la dicha Villa e su tierra le sea dada liçençia a los que traxeron por quien e commo e de la forma e manera que en la dicha ordenança rehecha en dicho de ochenta e quatro se contiene; e que por la dicha liçençia aya de dar a la dicha Villa, por averse adobado e cortido en su suelo e con sus aguas, de cada dozena de cordovanes çinco maravedís e de cada cuero vacuno tres maravedís e de cada cuero de terneras e bezerros e venados dos maravedis e de cada dozena de vadana tres blancas, e que jure la tal persona que es yuso propio la dicha coranbre, en non de otro alguno. E si de otra manera, otra persona alguna sacare o metiere alguna coranbre en la dicha Villa e su tierra, quier sea suyo - ageno, que lo // aya perdido e sea la terçia parte (para los) ${ }^{q}$ veedores e la terçia parte para el que lo (acusare) e la terçia parte para la dicha Villa o para (el arren)dador que lo arrendare o en fieldad, e que si lo tomare los dichos veedores (sean) las dos tercias partes suyas y asimis(mo, el) arrendador o fiel que lo tomaré e que $(. . .)^{s}$ e registros non se fagan ante otros escrivanos (salvo) ante el conçejo, segund dicho es. E que por es(ta) la dicha liçençia e tenor el dicho libro aya (...) de cada una quier sea de mucha contia (...), pero si alguno pasare de camino por el (dicho Madrid) e su tierra con algunas coranbres quier s(ea, corti)do o por adobar, que pueda levarlas si(n pena) alguna por la dicha Villa e su tierra.

Ley de como se han de sacar los cueros de las carneçerías de Madrid e su tierra e de como a de ser primeramente basteçida la Villa de ellos.

Otrosí, por quanto en las leyes susodichas (...) que en ninguna manera non se de liçençia para sacar (coranbres) algunas de los cueros de las carneçerías de esta (Villa) e su tierra; y en el arrendamiento que tiene fecho (el) arrendador que se obligó de dar carne a esta (dicha) Villa fasta San Juan de junio del año venide(ro) 
de noventa, con condiçión que pueda sacar de la dicha Villa e su tierra las dichas coranbres, ordenaron que pues se han de sellar por los dichos veedores de la dicha coranbre, se bastezca la dicha Villa porque poco quede para sacar de ella sin el derecho que ayuso deirá; e que por de aquí al dicho día de San Juan non se lleve derecho alguno de las dichas coranbres de las dichas carneçerias que asi se ovieren de sacar seyendo basteçida de ellas la dicha Villa porque su condiçión se guarde al dicho carniçero. $E$ ordenaron que, dende en adelante, non se arriende las dichas carneçerías con se(me)jante condiçión porque toda la coranbre que se sacare de la dicha Villa e su tierra se pague en derecho que ayuso diré, e si se arrendare que la tal condiçión non vala salvo si la Villa ordenare lo contrario en lo de la dicha carneçería por bien del pueblo en que intervengan todos estados, e que todas las cosas a esto tocante de estas coranbres juzguen qualquier de los regidores de la dicha Villa ante quien fuese, non embargante, lo que dize en la ley del año de ochenta y quatro que lo juzguen los dos regidores que regiesen cada mes, e que las liçençias se den asímismo por qualquier de ellos dichos regidores, visto con los dichos veedores segund suso dize en el dicho año de ochenta e quatro.

Otrosí, dixeron que por la graçia de Dios en esta Villa ay muchas personas que tratan en los dichos cueros e meten en ella mucha coranbre de muchas partes para lo cortir e adobar, e al tiempo que lo queiren sacar se les niega la liçençia non embargante que quieren dexar bastecimiento para la Villa, lo qual pareçe cosa inumana quitándoles su trato e considerando que es bien con la dicha Villa que en ella aya personas que traten, e asímismo, las grandes neçesidades de ella e de los pecheros sobre quien carga muchas derramas. Por ende, de consentimiento de los cortidores $e$ tratantes del dicho cortido acordaron que guardándose la orden de las dichas leyes del dicho alo de ochenta e quatro se haya de dar e dé la dicha liçençia de la forma e manera que suso dize e que ayan de pagar e paguen los que así sacaren la dicha coranbre, quier sean vecinos desta Villa o no, las contias de maravedis."

Otrosi ${ }^{2}$, que ningund cortidor non sea osado de sacar nin saque del noque ningund cuero vacuno curtido sin que llame para ello a los dichos veedores y esté presente a ello e vean si los dichos cueros están bien curtidos e si los dichos vieren, entonces los sales e sazonen (...) no pareçiere sellado los dichos veedores e fieles los puedan tener. 
Otrosí, que si los dichos cortidores a escuso sacaren coranbre alguna sin çedula e merçed e façiendo las diligençias contenidas en las dichas ordenanças que aya e incurra en las penas contenidas en las dichas ordenanças las quales se puedan leer asi por sabidas como por tomadas ${ }^{x}$.

En la Noble Villa de Madrid, doze dias del mes de octubre, año del nasçimiento de Nuestro Señor Ihesu Christo de mill e quatroçientos e noventa e tres años, en la posada del señor licenciado Cristobal de Torres, corregidor en la dicha Villa e su tierra por el Rey e la Reyna, Nuestros Señores, el dicho señor Antonio e Luis Dávila e Gonzalo de Monçón, regidores, e Juan de Salmerón e Juan de Çatres, que fueron por la dicha Villa señalados e diputados para faser e ordenar las ordenanzas sobre las coranbres e calçados de esta dicha Villa, e por ellos vistas las ordenanzas que sobre esto están fechas, fizieron e ordenaron las ordenanzas.

a. Ley...Villa) al margen izqdo., letra coetánea.- b. Ley... tierra) al margen izqdo., letra coetánea. $-c$. que ge lo vendieron) sobre la línea. $-d$. Ley...ferias) al margen izqdo., letra coetánea.e. Ley...coranbres) al margen izqdo., letra coetánea.- $f$. Ley... tomada) al margen izqdo., letra coetánea.- $g$. Ley...Madrid) al margen izqdo., letra coetánea.- $h$. Ley...malos) al margen izqdo., letra coetánea. - i. Y que...veedor) añadido posterior, de otra mano distinta.- j. Ley...curtidores) al margen izqdo., letra coetánea.$k$. Ley...deven) al margen izqdo., letra coetánea.- I. Este ofiçio...e) sobre la linea, añadido posterior de otra mano.- $m$. Ley de las penas) al margen izqdo., letra coetánea.- $n$. Ley...labrar) al margen izqdo., letra coetánea. - $\tilde{n}$. Ley...sacar) al margen izqdo., letra coetánea.- o. Leyes nuevas) al margen izqdo., letra coetánea.$p$. Ley...sacaren) al margen izqdo., letra coetánea.- $q$. Lo que va entre corchetes corresponde a notas del manuscrito que se han podido suplir.- $r$. tomare) to sobre la línea.- $s$. Los paréntesis en blanco corresponden a rotos que no se han podido suplir.$t$. Ley...ellos) al margen izqdo., letra coetánea. - u. susodichos) añade y tacha mss. A continuación tres líneas ilegibles de mano distinta.- $v$. A partir de aqui, y hasta el final, el manuscrito aparece escrito por mano distinta, sin duda posterior en el tiempo.x. Párrafo ilegible. 